\title{
Information behaviours in disadvantaged and dependent circumstances and the role of information intermediaries
}

Steven Buchanan*, Cara Jardine, \& Ian Ruthven

University of Strathclyde, Department of Computer and Information Sciences, Livingston Tower, 26

Richmond Street, Glasgow G1 1XH, UK.

Telephone: +44 (0)141548 3189; Fax: +44(0)1415484523

[Steven.Buchanan, Cara.Jardine, Ian.Ruthven]@strath.ac.uk

${ }^{*}$ Corresponding author

\begin{abstract}
The first empirical study focused exclusively on the information intermediary role in disadvantaged (socioeconomic) and dependent (support) circumstances. We report findings from semi-structured interviews and focus groups with 49 UK state and voluntary sector professionals providing support to young $(<21)$ mothers from areas of multiple deprivations.

We evidence an important information intermediary role with three key contributions to information behaviours in disadvantaged and dependent circumstances. Intermediaries: facilitate information needs recognition, and considered purposeful action within problematic situations; are a key source of information in themselves, and a key integrative connection to other external sources not otherwise accessed; and tailor and personalise information for relevance, and communicate via incremental and recursive cycles that take into account learning needs. We provide parameters for a theory of information intermediary intervention to guide future examination of an important and understudied role; and conceptualise important theoretical relationships between information behaviour and social capital, and in particular shared concepts of social integration, and the progressive and integrative intermediary role within.

Our findings have significant practical implications for public health policy and digital health strategies, as they evidence an important human information intermediary role amongst an at-risk group, with implications for disadvantaged and vulnerable populations more broadly.
\end{abstract}

Keywords: information behavior; information poverty; information intermediary; information literacy; health literacy; social capital; mothers.

Article classification: research paper

This is the peer reviewed version of the following article: Buchanan, S., Jardine, C. and Ruthven, I. (2019), Information behaviors in disadvantaged and dependent circumstances and the role of information intermediaries. Journal of the Association for Information Science and Technology, 70: 117-129, which has been published in final form at https://doi.org/10.1002/asi.24110. This article may be used for non-commercial purposes in accordance with Wiley Terms and Conditions for self-archiving. 


\section{Introduction}

Within information behaviour, the intermediary role (understood as people who act as information mediums or agents for others), has long been associated with librarians and educators, but has grown to encompass other information professions, and the concept of lay intermediaries (Abrahamson and Fisher, 2007). However, whilst the intermediary is recognised as, "a vital component in information behaviour" (Case and Given, 2016, p.362), there are few empirical studies explicitly examining the role, particularly in disadvantaged circumstances, and from the broader perspective of professionals outwith information professions occupying community-based support roles (see Background). Such a perspective is important, as in disadvantaged circumstances; a dependency on such individuals for information appears evident (e.g. Westbrook, 2009; Buchanan and Tuckerman, 2016), warranting further exploration.

\section{Background}

For the purposes of this study, we focused our attention on studies identifying an information intermediary role in disadvantaged circumstances. Given socio-technological trends, contemporary studies that consider the intermediary role in both the physical and digital space, and interplays between, are also important. We discuss the most relevant below.

Several studies have been undertaken in developing nations. Schilderman (2002) investigated the information needs of the urban poor in Peru, Zimbabwe, and Sri Lanka. Shilderman reports that, "people in low-income urban settlements have a complex range of information needs, many... unsolved" (2002, p.24), that "cannot be targeted effectively with mass messages" (2002, p8). Social networks are the primary information sources, with information conveyed largely via word of mouth. Reliability is a significant issue, compounded by a reluctance to interact with authoritative institutions due to issues of trust, and inappropriate formats and mediums of communication. Schilderman reports intermediaries (e.g. Government, Health, NGO) as having a key role, but being largely unsuccessful due to inadequate understanding of complex needs, and because dissemination, "relies too much on one-way communication often via inefficient infomediaries and does not specifically target the poor" (2002, p.47). Duncombe and Heeks (2002) report similar findings from Botswana, reporting an important but largely ineffective intermediary role, with information shared informally via social networks that leave many needs unmet and "perpetuating an insular existence" (2002, p.65). They argue that intermediaries can "bridge the financial, socio-cultural, and knowledge gaps" (2002, p.71), but to be more effective, need to: understand information needs; provide information in personalised formats; and extend the intermediary role beyond access to application of information.

Sabelli (2012) undertook a study in Urugay exploring the intermediary role of health, education, and social service professionals providing support to adolescent women in disadvantaged vulnerable situations. Participants are described as having multiple information needs not always recognized or expressed as such, and having 'little interest and ignorance about the existence of local resources and public services' (2012, p.7). Use of state and voluntary sector public access computing venues (PACs) providing Internet access, is described as "non-existent" (2012, p.8). Intermediaries are reported to provide a key role in increasing awareness of information needs, and directing to information sources, and described as providing, "an essential bridge between young women and their appropriation of information and knowledge processes, both for their personal and collective development” (2012, p.1).

Bailur (2010), investigating PACs underutilization in India, reports that PACs are highly dependent on the personality, motivation and ability of PAC staff as intermediaries, and their ability to establish trusting and inclusive environments. Bailur describes a "critical role... [that] greatly influences... success or failure in bridging digital divides" (2010, p.1). Gomez et.al. (2012), in a similar study in Colombian PACs provides further insight, reporting that, "Infomediaries play a critical role in understanding and meeting the information needs of the users" (2012, p.118), and describe three key

This is a preprint of an article accepted for publication in Journal of the Association for Information Science and Technology copyright @ [2018] (Association for Information Science and Technology) 
intermediary functions: sharing information in accessible and meaningful formats; helping users access information via basic training; and fostering and building relationships through "community development and empowerment of users to solve their problems and transform their realities" (2012, p.129). Highlighting the importance of empowerment, they describe effective intermediaries as those who know the difference between "giving someone a fish, and teaching them to fish" (2012, p.130).

Studies from developed nations report similar issues and remind us of enduring and transcendent human preferences for interpersonal communication. A study by Agada (1999) undertaken within a US African-American inner city community of multiple deprivations reports that "interpersonal sources were preferred over all other sources" $(1999$, p.74), with limited use of external sources due to issues of trust and credibility, compounded by information services not being "tailored to meet some of the everyday survival needs among this population" (1999, p.82). Agada (1999, p.82) highlights intermediaries as having a key role to "bridge the gap".

Wathen and Roma (2005) investigated health information behaviours amongst women in rural Canada with limited access to health services. Whilst the majority had access to Government digital and telephone health services thought to assist with remote access, the authors report low usage. Participants demonstrated a preference for interpersonal face-to-face information sources, and utilised a wide range of local intermediaries, ranging from health professionals, to more commonly, allied and alternative health care providers, and family and friends. Such intermediaries are identified as having, "a key role... in the [health] information seeking process... [providing] context about the health issue in question, links to more formal sources such as books, etc. and, importantly, validation, comfort and support." (2005, p.6).

Durrance et al (2006) investigating everyday information behaviours in a community setting within a US city zone of multiple deprivations, reports that members of local community groups provide an important intermediary role "critical to the information landscape of communities" (2006, p2). In particular, they variously: collect and share information and links within and across groups; "routinely... interpret, distill, and re-frame information" to make it more relevant and accessible to constituents (2006, p2); and prepare information for targeted dissemination and use. Durrance et al report that community-based intermediaries facilitate community problem solving because they are "close to the problem, [and] ....understand the needs associated with it" (p.12).

In summary, human intermediaries appear important to the meeting of information needs in disadvantaged circumstances, and appear to provide an important connection to external sources of information (the 'bridge' metaphor used by Agada, 1999, Duncombe and Heeks, 2002, Bailur, 2010, and Sabelli, 2012). However, ineffective and/or ill-defined intermediary practices are also reported, in particular related to intermediary understanding of information needs (Agada, 1999; Schilderman, 2002; Duncombe and Heeks, 2002), and effective methods of information dissemination and application (Schilderman, 2002; Duncombe and Heeks, 2002). With only five of the above studies involving intermediaries, and non exclusively focused on the intermediary role (and several with limited distinction between person and intermediary data); there is also limited empirical evidence from the intermediary perspective limiting our depth of insight and understanding of the role. There is also limited theoretical consideration of the intermediary role in relation to general theories and models of information behaviour. Consequently, there would appear to have been limited progress since Bailur concluded, "There appears to be insufficient research on these critical individuals" (2010, p.1). This raised two key research questions:

1. In disadvantaged and dependent circumstances, what is the information intermediary role?

2. In relation, how might we conceptualise the information intermediary role?

\section{Methodology}

This is a preprint of an article accepted for publication in Journal of the Association for Information Science and Technology copyright ( [2018] (Association for Information Science and Technology) 
A purposive approach to sampling defined key participant inclusion criteria as being a state or voluntary sector professional directly engaged in providing support to young mothers from areas of multiple deprivations (e.g. employment, education, health, crime). Recognising that participants might have a broad range of clients, it was made clear as part of invites that our focus was their interactions with disadvantaged mothers.

Young mothers from areas of multiple deprivations can be considered disadvantaged and dependent. They are more likely to be single parents, to have experienced family conflict/trauma, not to be in employment or education, and at risk of short and long term mental health issues (Trivedi et al, 2007); infant mortality rates are higher than older women (Torvie et al. 2015), and babies at greater risk of poor nutrition and care (Harron et al, 2016). Stress and anxiety are heightened, as are rates of depression (Raskin et al, 2016). Low literacy is also reported (e.g. Bennett et al, 2013). Notwithstanding such issues, motherhood can be a positive and transformative experience for young people (Duncan, 2007; Brand et al, 2014); however young mothers are subject to significant negative attention and stigmatisation. Shoveller and Johnson argue that public discourse on parenthood predominantly portrays young mothers as a societal problem, and encourages marginalisation and "a climate of sex-based shame" (2006, p.47). They argue that public health interventions have been preoccupied with risk and "what is wrong with the individual", as opposed to the environment, and that greater attention needs to be given to how to "transform youths' social contexts and structures" (2006, p.56). Brand et al discuss how this "deficit view of young motherhood" $(2014$, p.174) can lead to mothers concealing needs from professionals due to "fear of stigmatisation and lack of confidence" (2014, p.175). Brand et al report "strong evidence of the interrelationship between a young mother's support systems and experiencing a positive transition to motherhood" (2014, p.177), but that "service models that offer the right type of support for young mothers are limited" (2014, p.177). They highlight the need for "bottom-up" approaches to health care that foster meaningful relationships with young mothers and respond to individual needs. Such issues of marginalisation and concealment reinforced the appropriateness of our theoretical framework bringing together theories of information poverty with theories of social capital to better understand shared concepts of social integration, understood as participation, access, and engagement.

Chatman's (1996) theoretical framework for describing an impoverished information state draws on insider/outsider theories from the social sciences to explore how insider/outsider identity influences behaviours. Chatman argues that "Based on previous research, one can make a prima facie case that people who live in an arduous social landscape view outsiders with self-protective eyes" (1996, p.205). Chatman (1996) proposes four concepts defining the basis of an impoverished information world: deception (distortion of truth), risk-taking (aversion to risk), secrecy (intentional concealment), and situational relevance (immediate utility); and six propositional statements, that describe an impoverished information state as one in which people variously perceive themselves to be devoid of sources of help, are influenced by outsiders who withhold privileged access to information, adopt selfprotective behaviours in response to social norms, are mistrustful of the ability of others to provide useful information, withhold their true problems in the belief that negative consequences outweigh benefits, and selectively receive new information. Chatman reports that in impoverished circumstances, a stratification of information access occurs, with information needs and sources localised, and outside sources not usually sought in a "world on which norms and mores define what is important and what is not" (1996, p.205). Such concepts drew our attention to the applicability of social capital theory.

Widely recognised as a strong predictor of individual health and wellbeing, social capital refers to "features of social life - networks, norms and trust - that enable participants to act together more effectively to pursue shared objectives" (Putnam, 2000, p.2). Three types of social capital are commonly recognized (Putman, 2000; Woolcock and Narayan, 2000): bonding (close, immediate peer

This is a preprint of an article accepted for publication in Journal of the Association for Information Science and Technology copyright ( [2018] (Association for Information Science and Technology) 
and family connections); bridging (more distant connections with people of similar characteristics); and linking (institutional connections via people in authoritative positions). Recognising that "social capital can operate through the diffusion of information" (Drentea and Moren-Cross, 2005, p.924) and that state and voluntary sector agencies, "can contribute to the building of social capital by promoting the types of interaction and integration which enable social networking and by providing citizenship information resources" (Goulding, 2004, p.4); a particular strength of incorporating a social capital perspective is that it "shifts the focus of analysis from behaviour of individual agents to the pattern of relations between agents, social units and institutions" (Schuller et al., 2000, p.35).

Semi-structured interviews and focus groups were identified as appropriate data collection methods. Interviews (1 hr. duration) were semi-structured around everyday information needs, seeking preferences and issues that participants observed and dealt with during interactions with mothers. It was not our intention to develop comprehensive typologies of needs and sources, but identifying helped provide context and structure to discussions that primarily sought to explore interactions between participants and mothers, and the intermediary role within. Two of the three research team members conducted interviews. Interview transcripts were recorded and transcribed in full.

Focus groups (4 groups of 8-10 participants, $2 \mathrm{hr}$. duration) followed interviews and began with preliminary semi-structured discussions, followed by open discussions. A participatory approach encouraged discussion and simplified data collection. Participants were asked to initially identify and note (flipchart) the various information needs, sources utilised, and issues experienced by young mothers; and to then discuss what they themselves found difficult during information interactions with young mothers. Research team members (all) moderated groups with minimal intervention beyond instruction and prompts. Postgraduate students were recruited to note and transcribe discussions.

Data analysis incorporated deductive and inductive elements, with data disaggregated into meaningful categories via identification of patterns and regularities through iterative pattern coding and thematic analysis (utilising NVivo). Initial start-list codes were based on but not limited to, Chatman's (1996) concepts of information poverty (e.g. deception, risk-taking, secrecy, situational relevance), and concepts of social capital (e.g. bonding, bridging, linking (Putman, 2000; Woolcock, 2000)), reflective of the theoretical framework. Further codes were emergent from data, in particular those relating to intermediary interactions and influencing factors. Periodic code checking (multiple sample coding), was conducted by one team member independent to the first to validate developing code structures, with no notable variations found. Emergent themes were developed and refined iteratively including crosschecking (all team members) for coherence, consistence, and distinctiveness (Braun and Clarke, 2006).

Narrative analysis was conducted to provide a sense of temporal sequence to intermediary interactions, and to shift attention from "what happened" to "how people make sense of what happened" (Bryman, 2016, p.589). Narrative analysis of transcripts sought to identify 'stories' providing interconnections between information needs, contexts, and behaviours, and to gain insight into intermediary sense of role within recalled events. Participants were not required to provide narratives, but it is recognised that this can naturally occur as, "people perceive their lives in terms of continuity and process" (Bryman, 2016, p.590).

Ethical approval was obtained via Institutional Ethics Committee, with the study run in strict accordance with the University Code of Practice on Investigations of Human Beings. Informed written consent was obtained from all participants, who all participated voluntarily.

\section{Findings}

22 professional support workers were interviewed, and 36 participated in focus groups (9 of the latter

This is a preprint of an article accepted for publication in Journal of the Association for Information Science and Technology copyright @ [2018] (Association for Information Science and Technology) 
also interviewed, giving us 49 participants in total). Participants were family nurses, health visitors, social workers, and support group leaders, and represented 8 state and voluntary sector organisations/units providing health and family support services, with 5 of 8 working specifically with young mothers, and the remainder providing support for general population mothers encompassing young mothers. While none exclusively supported disadvantaged mothers, such mothers were confirmed as large parts of all caseloads.

Findings are presented reflecting the order of semi-structured discussions that explored the needs that formed the basis of information interactions, the sources utilised, and issues dealt with. A further category, factors enabling information interactions, was emergent from discussions.

\section{Information needs}

The information needs identifiable from participants' discussions were categorised as: pregnancy, baby care, finance, family relationships, education and employment, parent health, and housing. Two overarching themes emerged regarding multiplicity and recognition of needs.

With regard to multiplicity, participants described multiple and conflicting needs amongst mothers, many related to poverty (poverty described by one participant as one of the "biggest issues"). Participants routinely helped mothers with understanding state welfare, maternity grant and food and vitamin voucher entitlements, and access to food banks. Financial needs were often closely linked to housing needs and the fundamental need to provide their child with a habitable home that in situations of sub-standard accommodation or homelessness could supersede all other needs. For example, one commented, "Its hard to discuss singing and reading to your baby with someone who's worried about having nowhere to live". And another:

The right time is really, really important [to discuss needs other than housing], because for a lot of them, it wouldn't be appropriate... A couple of them actually said to me, 'I can't think about this now because my house is not sorted'. And for a lot of them, they've got to get that house; they've got to get that safe, secure base for their baby before they can... think about the other bits.

With regard to recognition, participants discussed a lack of awareness and/or understanding of needs amongst mothers. For example, bonding and attachment was described as an important need that could often be unfamiliar to young mothers from disadvantaged backgrounds. For example, one participant described attachment and bonding as a need of "greatest importance" requiring additional support, "as they have never experienced that kind of intimacy" during their own childhoods. Participants also discussed how some mothers could fail to recognise and/or normalise abusive and violent behaviours, requiring sensitive sharing of information over time to understand needs. One commented:

We do relationship work... and what a relationship should be like, so we do quite quickly become aware if something is not quite right... we've had parents say 'everyone has arguments and you get a wee slap' and then it's talking about that and saying 'no that's not normal...' .... It can be like a drip, drip, drip; sometimes lots of little things together can be a catalyst for change.

Participants described running group sessions that shared information on acceptable and unacceptable behaviours in relationships that could lead to constructive discussion and disclosure. During such sessions mothers often had questions regarding sexual relationships, and in relation, what constituted consent, one participant commenting, "That was quite scary, the consent, they didn't know". Another recalled a single session where, during such information sharing and discussion, three mothers disclosed that they had been victims of rape, and a fourth of serious assault.

\section{Information sources}

This is a preprint of an article accepted for publication in Journal of the Association for Information Science and Technology copyright ( [2018] (Association for Information Science and Technology) 
The information sources identifiable from participants' discussions were categorised as: support workers, family and friends, social media, websites, libraries, and books and leaflets. An overarching theme was a preference amongst mothers for interpersonal sources of information, and in relation, an important intermediary sourcing and connecting role.

Family and friends were important information sources for reasons of immediacy and trust, and due to a general reluctance amongst mothers to access unknown or unfamiliar external sources (i.e. other professionals, agencies or baby groups). One described family and friends as often the "first port of call". Another commented,

Word of mouth is a biggie, talking to friends is a biggie, going on the Internet and looking at stuff, definitely... phoning or going to buildings to talk to people, ... not so much.

Participants identified themselves as important sources and providers of information. Several believed that many of the mothers whom they worked with would not be able to find the information that they needed without their support. For example, one commented that it was, "very rare a parent will research themselves", and another described themselves as "probably their only link between getting information and not getting information". Where information provision was outwith participant expertise, participants would signpost mothers to other agencies. However, while some mothers would access signposted agencies themselves, many would not without support, including making telephone calls. One commented:

We can support them to a certain level... but there are things... out with our expertise and we have to get them to access additional services. And it's getting them to feel confident enough to do that.

Participants identified online sources as important, but had limited understanding of what was being used, and this was of great concern due to issues of literacy (see below). However, several participants also felt that many mothers have a preference for interpersonal sources of information. For example, one commented that many mothers "want a person to ask rather than look up a computer".

Books and leaflets are important, but have to be carefully selected and recommended by participants due to literacy and learning issues, and given issues of limited engagement with external agencies, provided directly via participants.

\section{Issues}

Participants discussed a number of issues that impacted information interactions, categorised as: selfesteem, low literacy, misinformation, information overload, upbringing, institutional bureaucracy, and practical access.

Self-esteem was considered a significant issue compounding issues of isolation and lack of peer support. For example, one participant commented that, "their [mothers] information needs would be met I think more readily if they had the confidence and self-esteem to access [information]"; another that:

Self-esteem... plays a massive part because that brings about... shyness and... awkwardness. It's not that they don't want to know, they just can't verbalise how they want to learn. And they... then miss out.

Age-related personal development was considered a contributory factor with many mothers still variously dependent upon their own parents/carers for many everyday tasks including making and

This is a preprint of an article accepted for publication in Journal of the Association for Information Science and Technology copyright ( [2018] (Association for Information Science and Technology) 
attending health appointments, and reluctant to make appointments themselves that required disclosure of personal information, or to request information on sensitive topics. Mothers could also be reluctant to attend support groups involving singing, dancing or reading in public. One participant commented that once attending a support group mothers could still be uncomfortable "bridging from a bespoke group to a wider group", and that this was important as for many mothers such groups could be their main or sole point of contact and socialisation with other mothers. Stigma was considered a significant contributory factor. For example, one participant commented that many mothers attending ante-natal classes or support groups felt "judged because maybe they're a young parent, maybe because they're a single parent" and that these feelings extended to recreational activities and travelling by public transport. Another recalled a midwife having told one mother "that was a bit silly having a child at your age", and then asking "what are you doing this for, is this so you can get a house?"

Low literacy, both reading and information, are considered significant issues. Participants felt that low literacy discouraged many mothers from seeking information themselves, and limited their access to and use of key information commonly distributed via websites, books and leaflets. Low literacy could also limit participation in support groups. For example, one participant commented:

Things like Triple $\mathrm{P}$ [Positive Parenting Programme] work for particular... people ...who like reading about things or coming along to things... if your literacy is not good then how are you going to do the homework that lots of parenting classes ask?

\section{Another commented:}

...they may not be able to read your leaflet, [as a] high percentage of parents... living in Glasgow have... very poor literacy. So we could hand them all the leaflets in the world [without effect]... so the thing about bounce and rhyme... and interventions like that, they are about... demonstration.

Participants discussed difficulties in identifying literacy issues, for while some mothers could be very open about reading difficulties, others, as one participant commented, could be "scared" to reveal such issues. Literacy issues also had to be distinguished from language issues amongst mothers who spoke English as a second language.

Information literacy is also a concern. For example, one participant described Google as "dangerous", with mothers often seeking "quick answers" to health questions that "makes them more anxious", and often not having the "ability to differentiate from good and bad". Another commented, "Its important we give them the proper information because if not they see it on a website and think because it has been published it must be true". Another commented:

Social media and the Internet can be great if you know what you are looking for, but things on Facebook which are run by other parents can be problematic. ... we knew of one... who was giving out advice on Facebook, that... had social work involvement... But then you can see if you are a parent and you are feeling a bit isolated how you could quite easily get sucked into that, even if the information is pretty poor.

Misinformation is an issue, and felt to be particularly problematic in the absence of a supportive relationship with a professional, with mothers often sourcing advice from family members rather than accessing external authoritative sources themselves. Participants often found advice from family and friends to be contradictory to current recommendations, requiring sensitive intervention. One participant commented:

There's a lot of family pressure... I have [had] a debate [with] three different mums that their own mothers have told them there's nothing wrong with baby walkers... [and] weaning... before six 
months. ....they know the [correct] advice because we've spoken about this for lots of visits. But... I think they want... reassurance that what they're saying to their mums is okay.

Independent online searches could also introduce misinformation, and lead to incorrect self-diagnosis, described by one participant as "increasingly common". Another commented, "They are reading about it online and diagnosing their own kids as being autistic or having attention deficit disorder - this is a big problem"; and another, discussing the challenges associated with convincing a mother that they are wrong in situations of self-diagnosis, that, "It's difficult to get through to them once they are convinced of it".

Issues of information overload and inappropriate information formats that fail to take account of low literacy levels and individual learning needs were discussed. For example, one participant identified "overwhelming volumes of text" as an issue, another "auto delivery of information". Another commented,

There is a problem with information overload - sometimes the practitioner is just too focused on delivering the script - they don't pause to break it down or try to make it understandable.

In such circumstances, participants felt that assumptions of understanding could be incorrectly made, compounded by issues of concealment. For example, one participant commented that mothers would often not admit, "that they did not understand what they were told". In such circumstances individual interactions were important. For example, one participant discussed the need to be able to "sensitively explore [understanding] one to one". Participants discussed how such individual responses could be difficult, if not impossible, within group settings.

Upbringing can be an issue, affecting awareness of needs, and engagement with professionals. Participants discussed how the way in which mothers had themselves been parented/cared for could impact upon how they interacted with their own children, and that those with difficult and/or traumatic backgrounds might not be aware of different approaches to parenting, and would not seek such information, and/or find it hard to contextualise and put into practice (e.g. attachment and bonding). Previous interactions in traumatic circumstances could also influence how receptive mothers are to intervention and advice.

Institutional bureaucracy is an issue. Participants discussed how many mothers found essential state services such as welfare systems too complex to understand, and had problems understanding terminology and completing forms. Often possessing multiple complex needs difficult to articulate, mothers often found themselves being repeatedly signposted between multiple agencies. Participant assistance was often required, but not always successful. One commented:

Sometimes you've maybe took two or three hours out of your diary to do something with a young person... and by the end of that you've still not actually achieved anything. So if that's what it's like for you, what's it like for them?

Instances of mothers being given incorrect or conflicting information whilst interacting with multiple agencies were recounted by several participants; and a lack of continuity in who mothers interacted with (e.g. multiple midwives) was also considered a significant issue that could discourage effective interactions (i.e. discouraging mothers from asking questions where no relationship existed). Several participants recounted witnessing poor treatment of mothers when accompanying them to external appointments, with mothers often left feeling ignored or dismissed before they could access the help and information needed. One commented:

This is a preprint of an article accepted for publication in Journal of the Association for Information Science and Technology copyright ( [2018] (Association for Information Science and Technology) 
I have went to places with young people. And I suppose I have a feeling around about how invisible they might be... How differently people speak to them and they speak to me even if I'm standing next to them.

Practical access issues related to transport and technology. Travel time and/or cost, accommodating infant routines, and difficulties travelling with prams on public transport could all discourage mothers from accessing support groups. Participants also discussed how many mothers did not possess a computer and that those that did often could not afford or were not eligible for home internet; and that while mobile phones were more common, usage is limited by prepaid credit.

\section{Factors enabling information interactions}

Participants discussed a number of factors that contributed to effective interactions, categorised as: continuous and trusting relationship; tailored and personalised information; and incremental cycles involving walkthrough, demonstration, and repetition.

A recurrent theme was the importance of building a continuous trusting relationship, described as an often difficult and gradual process. Participants discussed how mothers could initially be resistant to professional involvement in their lives, one commenting that many mothers felt that professionals would "try and catch them out" or "tell social work". Another commented that some mothers genuinely feared their "child would be taken off them". Another discussed how during this period, when they often knew little of the individual, finding a personalised "hook" to gradually share information in meaningful terms could be difficult. Identifying those in most need of help could also be difficult (with early intervention considered critical). Once a trusting relationship was established, mothers were generally more willing to share problems and ask for advice and assistance. For example, one participant commented, "They are quite guarded... so they get to know you and they trust you and... speak to you about things, or tell you things that are going on". Trust was recognised as important to acceptance of information. One participant commented, "If you build trust with them and you tell them that something is valuable... if they trust you then they'll accept that and then maybe try it out". Another commented:

I've got to have trusting relationship... it's a very intensive caring relationship, but a professional relationship. And there [are] maybe times... where you have to be quite direct... it could be something like... safe practice. So it could be... they're putting the baby on their tummy in the moses basket... contrary to health advice.

Continuity of relationship provided time to convey information in meaningful terms, addressing issues of comprehension. One participant commented:

In 10 minutes, they [health visitors] go through so many appointments. Rather than... saying, 'No, don't wean until he's six months' and then leaving, the worker that's there all the time might say, 'How are you? Oh, you've started weaning? Well, you know, you shouldn't really wean 'til six months. Here's the reason why.' And it's... because they've got more time. And that's what the girls are... saying, 'aye they did say that but they don't tell us why. So I just fed him at four months'. Once you tell them what the research is saying that they could get allergies if you wean them too early, it's like, 'All right, I didn't know that.' ... it sticks in her head.

Continuity of relationship allowed participants to observe progress, and whether mothers needed more or less individual support, with participants listening to and responding to individual needs over time, and gradually building up the mothers' confidence and self-efficacy. One commented:

You hold that persons hand, support them and show them how to do it... It might take two or three times for them to do it but eventually they will build up the confidence to... do it themselves. But 
the handholding is necessary... they do feel stigmatised, they go into places and do feel stigmatised by older parents.... Whether that's there or not, it's in their head that they are being frowned upon cos they are a young parent.

On-going relationships provided opportunity for regular positive feedback, and to build confidence and self-esteem amongst mothers, particularly in isolated and/or difficult circumstances. One participant described themselves as, "the only person that's managed to say some nugget of something positive in amongst it all". Another discussed the importance of "positive experiences" and "meaningful, thoughtful interventions". On-going relationships also allowed participants to build positive relationships with partners and family members, and via wider acceptance of their support role, help reduce potential sources of misinformation.

Tailored (group) and personalised (individual) information was considered key to supporting information and learning needs, and to ensuring understanding; and considered difficult within the practical constraints of support groups, compounded by some mothers concealing needs and/or pretending to understand, described by one participant as "reading but not understanding". Participants considered it important to make information resources accessible and meaningful, and to personalise delivery. Participants discussed the need for streamlining of printed resources, easy to read pictorial resources, and the use of demonstrative tools such as foetal dolls. One commented, 'Some... have literacy problems which compound the problems of information overload since they can't process the material they are given - we know they wont read big bits of literature'. Several described utilising visual aids and/or encouraging personalisation of resources. One described using foetal dolls to show various stages of baby development; another described reading through books and encouraging mothers to write in them and mark pages with post-it notes to, "make it relevant and make it their book" and to "use it whatever way will be helpful".

Participants considered it important to walkthrough information rather than simply distributing. One commented, "I think there are some mums that would go through everything they are given, read everything, but that's not the norm"; another, "It's about us using the material and actually sitting with the leaflet that we have in that day and actually using it with the baby... making it... relevant." Several described scenarios where they began by talking through common issues before explaining why particular information is important. For example, one commented:

The programme gives us an opportunity to really explore... behaviours and... looking after themselves as well as their baby. So, you know, when they're stressed how... that will impact on the baby's health... so we spent a lot of time... talking about cortisone and the impact of raised cortisone on a baby.

Participants discussed role modelling as an effective method of conveying information (managing tantrums, playing and bonding etc.), and discussed how needs were individual. For example, one commented:

The best way to get information across is role modelling - how can they do it if they have never seen it being done? ...some of them might have... no experience with babies, or there might be things about the way that they were parented that make it difficult - there is a massive difference between giving them a leaflet and showing them. With some families role modelling might... take a week, but for others it could be five years.

Role modelling was often subtly integrated into activities and games, described by one participant as "showing but... not showing". Participants also discussed utilising other mothers as role models. For example, one commented:

They listen to other young people...they see that other young people can progress... and have 
come through the same difficulties... and they know that there can be another option... for them.

Demonstrations are considered effective methods of conveying information, with it important to ground demonstrations in the problematic context. For example, one participant discussed how information on nutrition was often supported by participatory cooking and tasting sessions focused on, "affordable practical solutions".

Repetition is important. One participant described conveying to mothers the health risks of smoking and substance abuse as "a journey", and another as "a constantly reinforced message" requiring "revisiting all the time"; another described role modelling as providing information by "drip drip effect". A recurrent theme amongst participants was the importance of not automatically assuming understanding, and utilising on-going relationships to provide opportunities for questions to be repeated, complex topics to be revisited, and sensitive issues to be addressed at opportune times. For example, one participant commented:

Every day we talk about something different, but having said that, a lot of my work is repetition we are able to do that here because we have the time to repeat activities or conversations until we get the outcome... we want.

And another:

If they aren't in the mood [to talk]... but say a month later they want to go back to it. ...you revisit that. ....it's the therapeutic relationship. They know you. They know they can say to you... 'no I don't want to talk about it'. We've all been there. They have all said it's the continuity [that helps], a lot... will say during the anti natal period, 'no disrespect to the midwives... but l'm seeing a different face all the time'.

\section{Summary of key findings}

Our participants provide support to disadvantaged and dependent young mothers with multiple, interrelated, and at times competing needs, not always apparent or revealed, and often within sensitive situations. Our participants play a key role in identifying, understanding, and progressing information needs in the problematic context. Our participants are a key source of information in themselves, and play a key role in providing, directing, and connecting mothers to other sources of information both physical and digital, and addressing issues of misinformation. Our participants believe that many mothers would be unlikely to seek the information that they need without their support, particularly from external sources outwith immediate social networks, largely due to issues of stigma. Our participants also play a key role in conveying and interpreting information in meaningful terms that account for individual learning needs. In summary, there is evidence of an important contribution to information need recognition, information sourcing, and information comprehension.

\section{Discussion}

In discussing our findings we return to our research questions.

\section{In disadvantaged and dependent circumstances, what is the information intermediary role?}

An important intervention role is evident with three interwoven contributions to information behaviours in disadvantaged and dependent circumstances, categorised as: information need recognition; information sourcing; information comprehension.

Information need recognition

This is a preprint of an article accepted for publication in Journal of the Association for Information Science and Technology copyright ( [2018] (Association for Information Science and Technology) 
Our participant's report that mothers can be reluctant to reveal needs due to fear of negative consequences, can be unaware of needs due to background, and can suspend needs due to conflicting priorities. Situational and complex, there is evidence of unconscious needs (Taylor, 1968), dormant needs (Cronin, 1981), unmet physiological needs taking precedence over psychological needs (Maslow, 1943), self-protective secrecy and deception (Chatman, 1996), and the person-inprogressive situations (Dunne, 2002).

Intermediaries gradually overcome secrecy and deception via the building of trusting relationships, and through general reflective discussions exploring behaviours and common parenting issues, jointly uncovering gaps in understanding and identifying needs. One illustrative example was a session on sexual consent and unacceptable behaviours that uncovered several misunderstandings and included several disclosures of abuse, that in turn, identified needs relating to coping with and surviving abuse. Another was in relation to bonding and attachment, considered by the majority of participants to be a key need, but something that mothers could find difficult to understand and contextualise due to a lack of prior experience in their own childhoods; and not something that they could always give their full attention to when occupied by immediate problems such as uninhabitable housing. In such situations the intermediary role extends beyond simplistic one-way information provision to two-way sensitive recognition and understanding of needs, the former relatively straightforward in comparison to the latter, that recognises that needs are not always understood, revealed, prioritised, or acted upon, and may need to be returned to. In such circumstances, situational understanding informs personalised non-judgmental and considered action that reduces risk of rejection.

Previous studies discuss the importance of intermediary understanding of context of need (Duncombe and Heeks, 2002; Schilderman, 2002), and report issues concerning intermediary understanding of individual needs (Gomez at al, 2012; Sabelli, 2012). Our findings provide depth of insight into the multifaceted complexity of needs, and the participatory and progressive manner in which intermediaries facilitate needs recognition. Findings also evidence the importance of recognising the natural order of needs, and issues of receptiveness to other needs when fundamental basic needs (e.g. shelter) are unmet.

\section{Information sourcing}

Our participants report that many mothers do not actively seek information themselves due to a reluctance to ask questions, request advice or assistance, or engage with external groups or agencies, including health clinics, due to issues of self-esteem and stigma, and literacy and practical access. There is evidence of aversion to risk-taking (Chatman, 1996), passive information seeking (Wilson, 1996), seeking by proxy (McKenzie, 2003), and an intermediary bridging and linking role (Putman, 2000; Woolcock and Narayan, 2000).

Our participants report that while many of the needs of mothers are outwith their primary expertise, they are nonetheless supported, as our participants believe from experience that many mothers would be unlikely to seek the information that they need without their support, particularly on sensitive topics and/or from external sources. Our participants describe actively directing mothers to "safe" and "trusted" sources, assisting with the navigation of complex and bureaucratic state health and welfare systems, "handholding" during interpersonal interactions with external agencies, and "sensitively" intervening via redirection to authoritative sources to address issues of misinformation. Our participants consider themselves "vital" to information access, with one describing themselves as "probably their only link between getting information and not getting information".

Previous studies have utilised the 'bridging' metaphor to describe intermediaries (Duncombe and Heeks, 2002; Agada, 1999; Bailur, 2010; Sabelli, 2012). Our findings evidence an at times critical dependency on intermediaries when seeking information from external sources outwith immediate and predominantly insular interpersonal social networks, and provide insight into contributory affective 
factors.

Information comprehension

Our participants report that many mothers have difficulties understanding information due to learning difficulties, and issues of information overload and literacy; issues often not revealed that require sensitive incremental and iterative approaches to resolve, and information tailored, interpreted, and applied in meaningful terms. There is evidence of self-protective secrecy and deception, and situational relevance (Chatman, 1996), of enduring human preferences for interpersonal communication (Case and Given, 2016), and a need for constructive interventions that anticipate uncertainty and anxiety (Kulthau, 2004).

Our participants discussed the importance of sharing information in meaningful and natural language via incremental "drip drip" cycles involving walkthroughs, visual demonstrations, and role modelling; and cautioned against "auto delivery" and "overwhelming volumes of text" that would not be read. Cognisant to issues of overload, participants described gradually introducing topics via general reflective discussions of common everyday issues, and subtly integrating demonstrations into group activities and games that could be followed up individually. Individual approaches had to take into account that some mothers "can't verbalise how they want to learn", and can be "quite guarded" and "scared" to admit issues of comprehension. Continuity of one-to-one relationship between intermediary and mother is considered key to building a trusting relationship that allows progress to be observed, questions and conversations to be repeated, and complex topics and issues to be revisited. Participants also discussed how some mothers, due to background, might never have experienced many of the things now required of them as mothers. In such circumstances role modelling was important, as they "might... never [have] seen it being done before". Effective supporting texts were described as succinct, pictorial, and easy to read, with mothers encouraged to personalise them. Time is considered key to conveying information in meaningful terms, and recognising issues of selfesteem, it is considered important to provide positive experiences and feedback at every opportunity, as the intermediary might be "the only person that's managed to say... something positive".

Previous studies have discussed the importance of meaningful information formats (Duncombe and Heeks, 2002; Gomez et al, 2012), and the intermediary role in interpreting, distilling and re-framing information (Durrance et al, 2006). Our findings evidence issues of comprehension, and provide insight into constructive information intermediary behaviours, and in particular, the incremental and recursive nature of information cycles, and the personalised nature of meaningful information formats.

\section{How might we conceptualise the information intermediary role?}

Our findings evidence an important intermediary role pivotal to progressive constructive information behaviours in disadvantaged and dependent circumstances, which can be distilled into three propositional statements to explain relationships between key concepts, and provide parameters for a theory of information intermediary intervention to guide ongoing examination:

1. In situations of multiple needs, information intermediaries facilitate information needs recognition, and considered purposeful action, that takes account of the problematic context.

2. In situations of insular existence, information intermediaries are a key source of information in themselves, and a key integrative connection to other external sources not otherwise accessed.

3. In situations of poor comprehension, information intermediaries tailor and personalise information for relevance, and communicate via incremental and recursive cycles that take into account individual learning needs.

The above statements help conceptualise the intermediary role in relation to general models of information behaviour (i.e. being variously pivotal to information needs recognition, information

This is a preprint of an article accepted for publication in Journal of the Association for Information Science and Technology copyright @ [2018] (Association for Information Science and Technology) 
sourcing, and information comprehension in disadvantaged and dependent circumstances); and help conceptualise theoretical relationships between information poverty and social capital, and in particular, shared concepts of social integration (i.e. access, participation, and engagement) and the information intermediary bridging and linking role within. It is outwith the practical limits of this paper to discuss shared social integration aspects in depth, but a metamodel is proposed (see Figure 1), influenced by soft systems thinking (for a concise overview of soft systems thinking, see Checkland and Poulter, 2006), which encourages a holistic perspective of complex purposeful human activity in problematical social situations (with many interpretations of any declared 'purpose' possible; and in problematic situations, multiple interacting perceptions of reality, and multiple worldviews, possible). Soft systems thinking also recognises that people attempt to act purposefully within environments subject to individual situational constraints (understood as sociological, psychological, economic) that determine individual environment (system) boundaries, and in our context, the information sources accessible or accessed by the person.

At the core of the model are problematic situations and needs, which when recognised, initiate purposeful intermediary supported information processes, depicted as arrows. Recognition and understanding of information needs can require incremental and recursive cycles of intermediary intervention. Information processes and flow are two-way, and while depicted as linear, will often be cyclical at the sub-process level within. General models of information behaviour (e.g. Savolainen, 1995; Wilson, 1999) could be 'nested' within arrows to explain sub-processes and sociopsychological factors and relationships, as could our propositional statements (i.e. recognition, sourcing, and comprehension). Problematic situations and associated needs, which initiate processes, can be loosely or tightly coupled (i.e. new or sequential). Person and intermediary are denoted as figures, information sources as circle objects, and the environment boundary as a dotted line (with arrows illustrating potential inward/outward directions of boundary movement). Outwith the boundary is the broader un-accessed world including un-accessed information sources.

Figure 1. The expansive and integrative role of the information intermediary

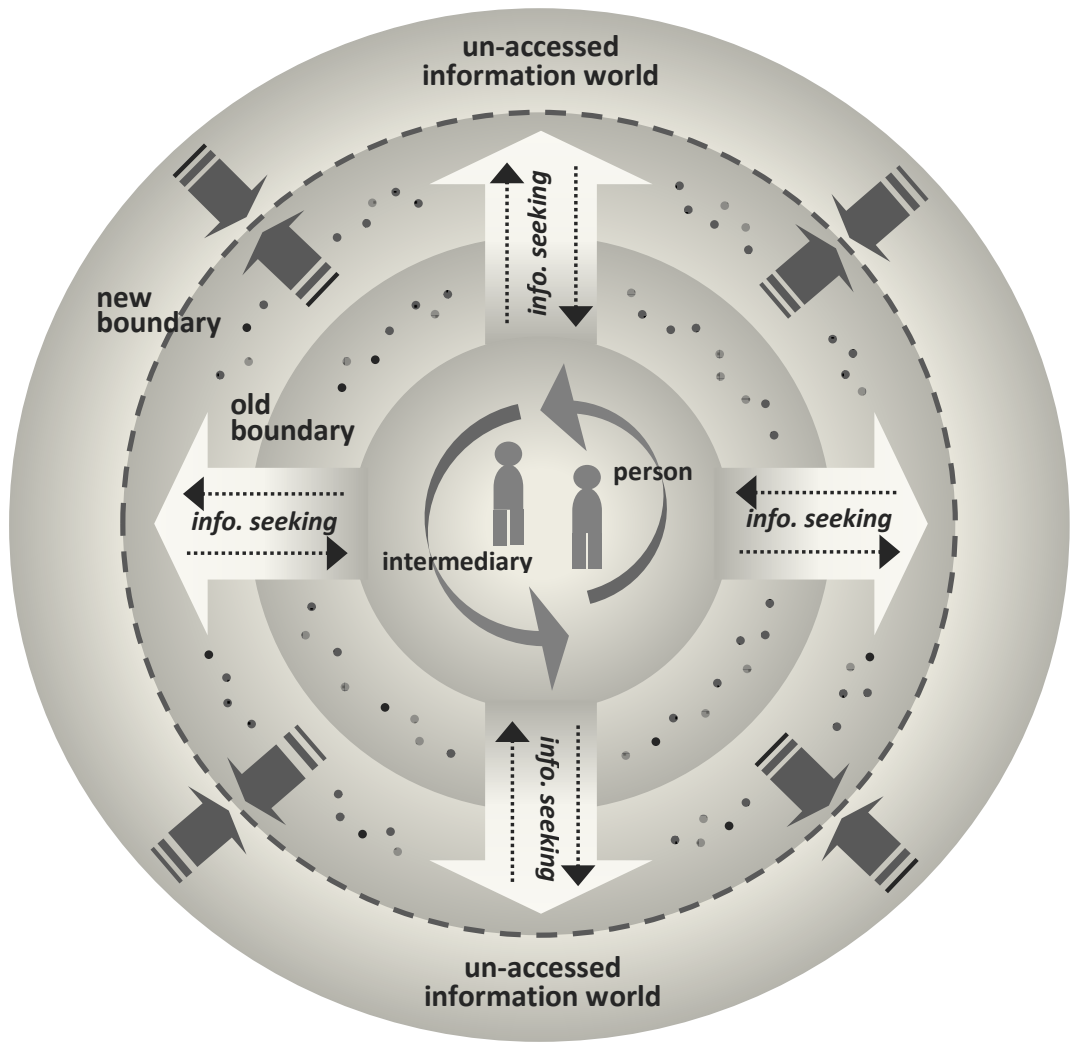

This is a preprint of an article accepted for publication in Journal of the Association for Information Science and Technology copyright ( [2018] (Association for Information Science and Technology) 
Viewed as a series of progressive integrative information seeking processes, information intermediaries assist the person with information needs recognition, information sourcing, and information comprehension, which progressively expands person knowledge, and via intermediary bridging and linking efforts to new information sources, progressively expands person (system) boundaries both physical and digital, and their social networks. Highly situational micro-transitions within could, as one participant discussed, "take a week, but for others it could be five years". It is also important to note that in practice, cycles might not always be progressive, and that boundaries might remain unchanged, or even contract. For example, our participants discussed several instances of mothers being reluctant to attend health clinics and withdrawing from support groups due to issues of stigma; and in other instances intermediary bridging and linking efforts might only establish temporary connections. However, the purposeful intention of the intermediary is nonetheless evidenced from our findings. The model is thus important for not only making the fluid system boundary of the person explicit, but also the expansive and integrative intermediary role within.

\section{Limitations and areas for further research}

We report from the underrepresented perspective of the intermediary, and while drawing upon the insightful cumulative experience of 49 professionals, we nonetheless report one side of a relationship, and reserve exploring young mother perspectives of the intermediary role for future research, including in relation to other sources of information and support. The applicability of our findings to disadvantaged and vulnerable populations more broadly is also an important area for further research.

Evidence of dependent relationships also raises important research questions regarding the development of self-efficacy (i.e. information literacy) in disadvantaged populations, and the role of non-information professionals engaged in everyday support roles.

\section{Conclusions}

Our participants, as information intermediaries, provide support to disadvantaged and dependent young mothers with multiple, interrelated, and at times competing information needs, not always understood or revealed; and often within sensitive situations. Via trusting non-judgemental relationships built over time, our intermediaries play a key role in recognising, understanding and progressing information needs in the problematic context. Extending beyond parenting to individual issues of poverty and personal development, many information needs are outwith their primary expertise, but are nonetheless supported as many mothers would be unlikely to seek the information that they need without intermediary support, particularly from formal external sources, due to issues of self-esteem and stigma, literacy, and practical access. Consequently, beyond being a key source of information in themselves, intermediaries play a key integrative role in connecting mothers to other information sources both physical and digital. Our intermediaries also play a key role in conveying and interpreting information in meaningful terms that account for individual learning needs, with information shared via incremental and recursive cycles involving walkthroughs and demonstrations.

Three propositional statements provide parameters for a theory of information intermediary intervention to guide future examination of this important role, positioning information intermediaries as variously pivotal to information needs recognition, information sourcing, and information comprehension in situations of problematic needs, insular existence, and poor comprehension. A metamodel conceptualises important theoretical relationships between information behaviour and social capital, and in particular shared concepts of social integration, and the progressive and integrative information intermediary role within the fluid system environment of disadvantaged and dependent people in problematic situations.

This is a preprint of an article accepted for publication in Journal of the Association for Information Science and Technology copyright ( [2018] (Association for Information Science and Technology) 
Beyond empirical and theoretical contributions, our findings have significant practical implications for public health policy and in particular digital health strategies, as they evidence an important human intermediary role amongst an at-risk group. In an era of digital transitions, our findings suggest that digital cannot be viewed as a primary form of information dissemination, and that holistic interpersonal approaches remain important. In relation, there are implications for information intermediary training and support, particularly outwith information professions. Our three propositional statements identify a core set of desirable competencies for future professional skills development programs.

\section{Acknowledgments}

This research was funded by ESRC grant ES/L012634/1: Understanding the Information Needs of Young First Time Mothers from Areas of Multiple Deprivation. 
Abrahamson, J.A., \& Fisher, K.E. (2007). What's past is prologue: towards a general model of lay information mediary behaviour. Information Research, 12.

Agada, J. (1999). Inner-city gatekeepers: an exploratory survey of their information use environment. Journal of the American Society for Information Science and Technology, 50(1), 74-85.

Bailur, S. (2010). The liminal role of the information intermediary in community multimedia centres. In Proceedings of the 4th ACM/IEEE International Conference on Information and Communication Technologies and Development, 5. ACM.

Bennett, I. M., Frasso, R., Bellamy, S. L., Wortham, S., \& Gross, K. S. (2013). Pre-teen literacy and subsequent teenage childbearing in a US population. Contraception 87(4), 459-464.

Brand, G., Morrison, P., \& Down, B. (2014). How do health professionals support pregnant and young mothers in the community? Women and Birth, 27(3), 174-178.

Braun, V., \& Clarke, V. (2006). Using thematic analysis in psychology. Qualitative research in psychology, 3(2), 77-101.

Bryman, A. (2016). Social research methods. Oxford University Press, Oxford

Buchanan, S. \& Tuckerman, L. (2016). The information behaviours of disadvantaged and disengaged adolescents. Journal of Documentation, 72(3), 527-548.

Case, D.O., \& Given, L.M. eds. (2016). Looking for Information: A Survey of Research on Information Seeking, Needs, and Behavior. Emerald Group Publishing.

Chatman, E. A. (1996). The impoverished life-world of outsiders. Journal of the American Society for Information Science, 47(3), 193-206.

Checkland, P., \& Poulter, J. (2006). Learning for action: a short definitive account of soft systems methodology and its use for practitioner, teachers, and students. Chichester: Wiley.

Cronin, B. (1981). Assessing user needs. Aslib Proceedings, 33(2), 37-47.

Drentea, P., and Moren-Cross, J.L. (2005). Social capital and social support on the web: the case of an internet mother site. Sociology of Health \& IIIness, 27(7), 920-943.

Duncan, S. (2007). What's the problem with teenage parents? And what's the problem with policy?. Critical social policy, 27(3), 307-334.

Duncombe, R., \& Heeks, R. (2002). Enterprise across the digital divide: information systems and rural microenterprise in Botswana. Journal of International Development, 14(1), 61-74.

Dunne, J.E. (2002). Information seeking and use by battered women: a "person-in-progressivesituations" approach. Library \& Information Science Research, 24(4), 343-355.

Durrance, J.C., Walker, D., Souden, M., \& Fisher, K.E. (2006). The role of community-based, problemcentered information intermediaries in local problem solving. Proceedings of the American Society for Information Science and Technology, 43(1), 1-17.

Gomez, R., Fawcett, P., \& Turner, J. (2012). Lending a visible hand an analysis of infomediary behavior in Colombian public access computing venues. Information Development, 28(2),117131.

Goulding, A. (2004). Editorial libraries and social capital. Journal of Librarianship and Information Science, 36(1), 3-6.

Harron, K., Gilbert, R., Cromwell, D., Oddie, S., \& van der Meulen, J. (2016). Adversity and risk of poor birth and infant outcomes for young mothers: a population-based data-linkage cohort study. The Lancet, 388, S54.

Kuhlthau, C.C. (2004). Seeking meaning: A process approach to library and information services. Libraries Unltd Incorporated.

Maslow, A.H. (1943) A theory of human motivation. Psychological review, 50(4), 370.

McKenzie, P.J. (2003). A model of information practices in accounts of everyday-life information seeking. Journal of Documentation, 59(1), 19-40.

Putnam, R. (2000) Bowling Alone: The Collapse and Revival of American Community. New York: This is a preprint of an article accepted for publication in Journal of the Association for Information Science and Technology copyright ( [2018] (Association for Information Science and Technology) 
Simon and Schuster.

Raskin, M., Easterbrooks, M.A., Lamoreau, R.S., Kotake, C., \& Goldberg, J. (2016). Depression Trajectories of Antenatally Depressed and Nondepressed Young Mothers: Implications for Child Socioemotional Development. Women's Health Issues, 26(3), 344-350.

Sabelli, M. (2012). Information behaviour among young women in vulnerable contexts and social inclusion: the role of social mediators. Information Research, 17(4).

Savolainen, R. (1995). Everyday life information seeking: approaching information seeking in the context of "way of life". Library \& information science research, 17(3), 259-294.

Schilderman, T. (2002). Strengthening the knowledge and information systems of the urban poor. ITDG, Rugby. Available at: https://practicalaction.org/docs/ia3/kis-urban-poor-report-2002.pdf

Schuller, T., Baron, S., \& Field, J. (2000). Social capital: a review of critique, in Baron, S., Field, J. \& Schuller, T. (Eds), Social Capital: Critical Perspectives, Oxford University Press, Oxford, 1-38.

Shoveller, J. A., \& Johnson, J. L. (2006). Risky groups, risky behaviour, and risky persons: Dominating discourses on youth sexual health. Critical public health, 16(1), 47-60.

Taylor, R.S. (1968) Question-negotiation and information seeking in libraries. College \& research libraries, 29(3), 178-194.

Torvie, A. J., Callegari, L. S., Schiff, M. A., \& Debiec, K. E. (2015). Labor and delivery outcomes among young adolescents. American journal of obstetrics and gynecology, 213(1), 95-e1.

Trivedi, D., Bunn, F., Graham, M., \& Wentz, R. (2007) Update on the Review of Reviews on Teenage Pregnancy and parenthood. Centre for Research in Primary and Community Care. Available at: http://www.nice.org.uk/nicemedia/pdf/TeenagePregnancyUpdateReviewFeb08.pdf

Wathen, C.N., \& Roma, H. (2005). An examination of the health information seeking experiences of women in rural Ontario, Canada. Information Research, 11(4), n4.

Westbrook, L. (2009). Crisis information concerns: Information needs of domestic violence survivors. Information Processing \& Management, 45(1), 98-114.

Woolcock, M., \& Narayan, D. (2000). Social capital: Implications for development theory, research, and policy. The world bank research observer, 15(2), 225-249.

Wilson, T.D. (1999). Models in information behaviour research. Journal of Documentation, 55(3), 249270. 